\title{
Articles
}

\section{Perceived Relationship Dissolution and Sexual Orientation of a Hypothetical Ex-Partner as a Threat to Identity}

\author{
Stephen Reysen ${ }^{* a}$, Iva Katzarska-Miller
}

[a] Department of Psychology, Texas A\&M University-Commerce, Commerce, United States. [b] Transylvania University, Lexington, United States.

\begin{abstract}
We examined the effect of participants' beliefs regarding origins of sexuality and the sexual orientation of a partner initiating the termination of a relationship on participants' emotional experience and perceived harm to one's public identity. Self-identified heterosexual participants who endorsed the belief that sexual orientation is either innate or a choice were asked to imagine that a relationship partner left them for either a same-sex or opposite-sex relationship partner. A mediated moderation analysis showed that, compared to when the ex-partner was straight, participants with a belief that sexual orientation is innate believed the gay ex-partner was not intentionally attempting to harm their public identity and perceived less damage to their public identity, which resulted in less anger.
\end{abstract}

Keywords: threat to public identity, relationship dissolution, attribution of sexual orientation, intention to harm, anger

Interpersona, 2013, Vol. 7(1), 63-76, doi:10.5964/ijpr.v7i1.113

Received: 2013-02-20. Accepted: 2013-05-27. Published: 2013-06-28.

*Corresponding author at: Department of Psychology, Texas A\&M University-Commerce, Commerce, TX, 75429, United States. E-mail: Stephen.Reysen@tamuc.edu original work is properly cited.

The breakup of a meaningful romantic relationship can represent a major life event and can have emotional and behavioral implications for both partners (Sbarra \& Emery, 2005; Sbarra \& Ferrer, 2006). The majority of relationship dissolution research examines topics such as attachment styles (e.g., Davis, Shaver, \& Vernon, 2003), emotional reactions and coping strategies (e.g., Sbarra \& Emery, 2005), predictors of breakup such as communicative styles (e.g., Gottman et al., 2003), and attractiveness of alternative relationships (e.g., Simpson, 1987). However, often neglected in personal relationship research is the acknowledgement that romantic couples are embedded in a larger social context (i.e., friends, family, culture) that has implications for the individuals in the relationship (e.g., Felmlee, 2001; Sprecher, 2011). People outside the relationship dyad may view the two partners as a single unit (Heider, 1958), which can lead the couple and others outside the couple to form a separate identity-a relationship identity (Felmlee \& Sprecher, 2000; Felmlee, Sprecher, \& Bassin, 1990; Lewis, 1973).

Just as individuals attempt to actively manage the impression others hold of them (Goffman, 1959; Leary, 1995; Schlenker, 1980), so relationship partners attempt to manage the impression others hold of the couple (Afifi \& Steuber, 2009; Kunkel, Wilson, Olufowote, \& Robson, 2003; Steuber \& Solomon, 2011). Individuals in relationships are faced with the task of balancing the goals of maintaining a positive and distinct individual identity while also maintaining the relationship identity. Research shows a preference for protection of individuals' public identity over that of the relationship identity (Afifi \& Steuber, 2009). For example, people are more likely to forgive a partner's 
infidelity if less people are aware of the transgression compared to when the knowledge of the transgression is potentially widely known by others (Afifi, Falato, \& Weiner, 2001). In this situation, if a partner's infidelity is known by others the partner is more likely to protect their personal identity by breaking up the relationship, yet if knowledge of the infidelity is not widely known the partner is more likely to forgive the other partner to protect the relationship identity. Given the fact that one's relationship has important implications for each partners' self-concept (Aron et al., 2004; Chen, Boucher, \& Tapias, 2006), the dissolution of a relationship affects not only the individuals' selfconcepts (Lewandowski, Aron, Bassis, \& Kunak, 2006), but also how others outside the relationship will view them (Doering, 2010). Relationship dissolution is therefore a potential threat to not only how one views oneself, but also how others view each partner. In the present paper we examine the influence of the belief in the immutability of sexual orientation and sexual orientation of the ex-partner following the termination of a relationship on emotion as a perceived threat to individuals' public identity.

\section{Interpersonal Threat to Public Identity}

We define an interpersonal threat to public identity as a situation where another person illegitimately and intentionally attempts to undermine one's freedom to display a valued and distinctive public identity (Gibson \& Reysen, 2012; Snider \& Reysen, 2011). This definition has four important features, including (1) the perception that the other person's behavior is intentional, (2) the perception that the other person's behavior is illegitimate, (3) the individual values the aspects of the public identity, and (4) the behavior undermines one's freedom to display the valued identity. The threat is subjective since each component represents perceptions of the other and the self. Furthermore, we posit that the perceived threat results from the interaction between the person and the environment. For example, learning that another person is secretly attempting to poach one's partner may be less threatening to the extent that the relationship was already troubled (i.e., the relationship is devalued). In this example, the person (i.e., perceived value of continuing the relationship) interacts with the environment (i.e., context of learning about another person attempting to poach a partner) to affect an outcome (i.e., perception of threat).

Past research on threats to public identity, such as embarrassment (Leary, Landel, \& Patton, 1996) and public failure (Greenberg \& Pyszczynski, 1985), focused on phenomenon where the actor was the cause of the threat. Interpersonal threats to public identity differ from the above threats in that another person is to blame, and the victim perceives the other person as illegitimately and intentionally attempting to impede one's freedom to display one's identity. Prior research (Gibson \& Reysen, 2012; Reysen, Landau, \& Branscombe, 2012; Snider \& Reysen, 2011) shows the primary responses to interpersonal public identity threats are anger and a negative evaluation of the other person (e.g., unlikable, dishonest). Furthermore, there is a perception that the other person is intentionally attempting to harm the victims' identity, and the perception of harm to their public identity mediates the relationship between the threat and felt anger.

\section{Relationship Dissolution as Threat to Public Identity}

Prior research on relationship dissolution shows that anger is commonly found to be reported by breakup recipients (Perilloux \& Buss, 2008; Sbarra \& Emery, 2005; Sbarra \& Ferrer, 2006), while less emotional distress is experienced by the individual initiating the breakup (i.e., breakup initiator) (Hortacsu \& Karanci, 1987; Perilloux \& Buss, 2008). The breakup recipient may view the breakup initiator as intentionally trying to harm his or her public identity, and thus experience anger toward the initiator of the breakup. Because a romantic partner becomes integrated and expands one's self-concept (Aron et al., 2004), relationship dissolution leads to a loss of identity characteristics that have been included in the self-concept during the relationship (Lewandowski et al., 2006). In this respect, if a partner initiates a breakup he or she is taking aspects of the self away from the breakup recipient. 
Others (e.g., friends and family) may have come to view and interact with a relationship partner in terms of their couple identity (Felmlee \& Sprecher, 2000; Felmlee et al., 1990). Once a partner terminates the relationship, others will have to revise their view of the individual, which may represent the loss of being treated in accordance with the prior couple identity. Indeed, both partners will attempt to manage their personal public identities after the relationship has ended (Doering, 2010; Kunkel et al., 2003). In a qualitative study examining the impression management strategies post relationship dissolution, Doering (2010) found a common theme among the breakup recipients to externalize the responsibility for the breakup by blaming the dissolution of the relationship on the breakup initiator. Together, the relationship dissolution research points to the notion that one's relationship identity is a valued aspect of one's public identity, and that after a partner ends the relationship the breakup recipient responds with anger toward the blameworthy partner. In effect, the breakup recipient appears to be experiencing a threat toward their public identity.

\section{Belief of Immutability of Sexual Orientation}

A wealth of research has shown that the perception that homosexuality is uncontrollable, innate, or immutable is strongly associated with positive attitudes toward gays and lesbians and greater support for gay rights policies (Blackwell, 2008; Haider-Markel \& Joslyn, 2008; Haslam \& Levy, 2006; Herek \& Capitanio, 1995; Lewis, 2009; Whitley, 1990). Indeed, when provided with a biological explanation of sexual orientation (vs. an ambiguous explanation or no explanation) heterosexual men express less antigay prejudice (Falomir-Pichastor \& Mugny, 2009). However, no research has examined the influence of belief in the immutability of sexual orientation on emotional reactions to a breakup. If the initiator of a breakup is gay (vs. straight), the heterosexual non-initiator of the breakup may experience less anger and view the ex-partner more favorably if the participant believes that the expartner's sexual orientation is immutable (vs. a choice). In such an instance (i.e., sexual orientation is immutable and the initiator of the breakup is gay), the heterosexual recipient of the breakup may perceive the breakup initiator as not intending to harm one's public identity and subsequently experience a lower intensity of anger because the cause of the breakup was uncontrollable. One method to test the model suggested above is mediated moderation.

Mediated moderation models test the dynamic interaction between person and context variables on an outcome through potential mediators (see Lyons, Reysen, \& Pierce, 2012; Morgan-Lopez \& MacKinnon, 2006; Muller, Judd, \& Yzerbyt, 2005). Thus, mediated moderation models highlight the intermediary process by which interactions between a person and the environment influence particular outcomes. Following the suggestions outlined above, the person variable of belief in the immutability of sexual orientation (moderator) should interact with the sexual orientation of the partner initiating the breakup (independent variable) to predict felt anger (outcome) through the perception of threat to one's public identity (mediator). A significant mediated moderation model as described would show the interactive nature of interpersonal threats to public identity, and show how relationship dissolution is a threat to one's public identity.

\section{Present Study}

The purpose of the present study is to examine the influence of the belief in the immutability of sexual orientation and sexual orientation of the ex-partner following the termination of a relationship on emotion due to the perceived threat to public identity. In the present study, we asked self-identified heterosexual participants who either believe sexual orientation is a choice or innate to imagine themselves in a romantic relationship that was positively valued by them and close others (i.e., friends and family). Participants were then told that their partner leaves them for either a same-sex or opposite-sex relationship and rated felt anger, perception of the ex-partner, and harm to 
public identity. We predict an interaction between belief in the immutability of sexual orientation and the sexual orientation of the ex-partner. If participants perceive sexual orientation to be innate (vs. choice) they should view a gay ex-partner favorably because they are ending the relationship for a reason that is outside their control, and therefore not intentionally attempting to damage the breakup recipient's public identity. However, if participants perceive sexual orientation to be a choice (vs. innate) we predict an equal degree of anger and negative perceptions of the ex-partner regardless of the ex-partner's reported sexual orientation. If participants perceive sexual orientation to be a choice, then the ex-partner is choosing to end the relationship presumably due to dissatisfaction with some aspect of the person. In other words, if sexual orientation is innate there is a clear reason for a gay partner to end the relationship, however if it is a choice others can attribute the reason for the breakup to be due to some aspect of the non-initiator, and is therefore damaging to their public identity. In fact, participants that believe sexual orientation to be a choice may perceive a greater threat to their public identity fearing that others may comment that they turned their ex-partner gay. Thus, we predict an interaction between participants' belief of the immutability of sexual orientation and the reported sexual orientation of an ex-partner on felt anger, perception of the ex-partner (likable, honest), harm to one's public identity, and perception of intent of the ex-partner to harm participants' identity.

Following past research on interpersonal threats to public identity (Gibson \& Reysen, 2012; Snider \& Reysen, 2011), we predict perceived damage to one's public identity and the perception that the ex-partner is intentionally trying to harm one's identity will serve as mediators between the interaction (immutability of sexual orientation belief $X$ sexual orientation of ex-partner) and felt anger. Thus, we predict a mediated moderation model. Following the suggestions outlined above, the person variable of belief in the immutability of sexual orientation (moderator) should interact with the sexual orientation of the partner initiating the breakup (independent variable) to predict felt anger (outcome) through the perception of threat to one's public identity (mediator).

\section{Method}

\section{Participants}

Participants (Men: $n=97 ; M_{\text {age }}=22.10, S D=6.38$; Women: $n=109 ; M_{\text {age }}=20.61, S D=4.97$ ) received partial course credit toward their introductory psychology requirement.

\section{Design and Procedure}

During a prescreen survey conducted at the beginning of the semester participants were asked to complete a measure regarding the cause of sexual orientation and to rate their own sexual orientation. Participants were eligible to participate in the present study if they rated themselves as heterosexual, and if they scored high (top 30\%: sexual orientation is innate) or low (bottom 30\%: sexual orientation is a choice) on a measure of attribution of cause of sexual orientation. After reading and signing an informed consent form, participants were randomly assigned to read about a romantic partner ending a relationship to be with either a same-sex (gay partner) or oppositesex (straight partner) person. Thus, the study is a 2 (belief of cause of sexual orientation: choice vs. innate) $X 2$ (ex-partner sexual orientation: gay vs. straight) between-subjects design. Following the vignette, participants rated felt anger, perceived honesty and likability of the ex-partner, perceived intention of the ex-partner to harm the participant, perceived harm to the participant's public image, and demographic items (i.e., gender, age, current relationship status). Participants were then debriefed and thanked. 


\section{Experimental Materials}

Prescreen measures - Participants were asked to rate their sexual orientation on a single item ("Please rate your sexual attraction to members of the opposite sex"), from $1=$ attracted only to the same-sex to $7=$ attracted only to the opposite sex. Only participants who selected a six or seven on the 7-point Likert-type scale were eligible to participate. Three items (e.g., "Sexual orientation is caused by biological factors such as genes and hormones") were adopted from prior research (Hegarty, 2002; Hegarty \& Pratto, 2001) and combined to form an index concerning belief of the origin of sexual orientation $(\alpha=.85)$. Items were rated on a 7-point Likert-type scale, from 1 $=$ strongly disagree to $7=$ strongly agree. Higher scores indicate a belief that sexual orientation is biological and innate, and lower scores indicate that it is a choice. Only participants with combined scores in the bottom and top $30 \%$ were eligible to participate in the present study. ${ }^{1}$

Vignette - Participants were asked to imagine that they were in a positive relationship for the past two years with an opposite-sex partner ("You have been dating a guy [girl] for the past two years. The relationship is going great. You really have fallen for this guy [girl]. All of your friends and family like him [her]"). Participants were then told that the partner broke up with them for either a same-sex ("One day your boy[girl]friend tell you that he[she] is leaving you for another guy[girl]") or an opposite-sex partner ("One day your boy[girl]friend tell you that he[she] is leaving you for another girl[guy]"). Thus, participants were asked to imagine that they were in a positive relationship that valued others (i.e., friends and family) approved, and that the partner broke off the relationship to be with either a same-sex or opposite-sex person.

Dependent measures - Participant responses regarding how they felt "right now" on two emotion terms (angry, mad) were combined to form an anger index ( $\alpha=.79)$. An 8-item (e.g., "I would say my ex is honest") measure of perceived honesty was adapted from prior research (Reysen, 2008) to assess the perception of the ex-partner as honest $(\alpha=.89)$. Nine items (e.g., "My ex is likeable") were adapted from prior research (Reysen, 2005) to assess the perceived likeability of the ex-partner $(\alpha=.90)$. Two items ("My ex is purposefully trying to hurt me," "My ex is intending to hurt me") were combined to assess the perception of intention to harm ( $\alpha=.86)$. Three items (e.g., "My ex is hurting my public image," "My ex is hurting my image") were combined to assess the perception that the ex-partner is damaging the participant's public identity $(\alpha=.86)$. Items were rated on a 7-point Likert-type scale, from 1 = strongly disagree to 7 = strongly agree. Lastly, participants were asked to provide their age, gender, and current relationship status.

\section{Results}

\section{Mean Differences}

To examine the effect of belief of origin of sexuality and sexual orientation of the ex-partner, we conducted a 2 (belief of origin: choice vs. innate) X 2 (sexual orientation of ex-partner: straight vs. gay) between-subjects MANOVA on the dependent variables. ${ }^{2}$ The omnibus test for the interaction between participants' belief of the origin of sexuality and the ex-partner's sexual orientation was significant, Wilks' $\Lambda=.88, F(5,197)=5.36, p<.001, \eta_{p}{ }^{2}=$ $.12{ }^{3}$ As predicted, interactions were found for each of the dependent variables (see Table 1 for means, standard deviations, and interaction statistics). Simple effects analyses were conducted to examine the interactions. 
Table 1

Means (Standard Deviations) for the Interaction Between Belief of Origin of Sexual Orientation and Sexual Orientation of Ex-Partner

\begin{tabular}{|c|c|c|c|c|c|c|c|}
\hline \multirow[b]{2}{*}{ Variable } & \multicolumn{2}{|c|}{ Choice } & \multicolumn{2}{|c|}{ Innate } & \multirow[b]{2}{*}{$F(1,201)$} & \multirow[b]{2}{*}{$p$-value } & \multirow[b]{2}{*}{$\eta_{p}^{2}$} \\
\hline & Gay & Straight & Gay & Straight & & & \\
\hline Anger & $5.98(1.19)_{a}$ & $6.02(1.26)_{a}$ & $4.45(1.85)_{\mathrm{b}}$ & $5.95(1.24)_{\mathrm{a}}$ & 13.69 & .000 & .064 \\
\hline Likeable & $2.43(1.23)_{a}$ & $2.17(1.08)_{a}$ & $3.47(1.15)_{\mathrm{b}}$ & $2.31(0.87)_{a}$ & 8.67 & .004 & .041 \\
\hline Honest & $2.21(1.11)_{a}$ & $2.40(1.25)_{\mathrm{ac}}$ & $4.06(1.38)_{b}$ & $2.83(1.08)_{\mathrm{C}}$ & 17.57 & .000 & .080 \\
\hline Intent to Harm & $3.46(1.63)_{a}$ & $4.19(1.82)_{\mathrm{b}}$ & $2.01(1.20)_{\mathrm{C}}$ & $3.96(1.62)_{\mathrm{ab}}$ & 7.65 & .006 & .037 \\
\hline Harm to Identity & $4.90(1.65)_{a}$ & $4.32(1.66)_{\mathrm{b}}$ & $2.86(1.62)_{\mathrm{C}}$ & $4.25(1.49)_{b}$ & 19.36 & .000 & .088 \\
\hline
\end{tabular}

Note. Means with differing subscripts are significantly different $(p<.05) .7$-point Likert-type scale, $1=$ strongly disagree to $7=$ strongly agree .

Anger - Participants who held the belief that sexual orientation is innate felt less angry when their ex-partner was reported to be gay rather than straight, $F(1,205)=28.57, p<.001, R^{2}=.19$. Participants who held the belief that sexual orientation is a choice were angry regardless of the ex-partner's reported sexual orientation, $F(1,205)$ $=.02, p=.89$. When the ex-partner was said to be gay, participants who believe sexual orientation is a choice reported greater anger than participants who believe sexual orientation is innate, $F(1,205)=31.62, p<.001, R^{2}$ $=.19$, while participants expressed an relatively equal degree of anger regardless of belief when the ex-partner was said to be straight, $F(1,205)=.06, p=.80$.

Likeability - Participants who held the belief that sexual orientation is innate rated the ex-partner as more likeable when the ex-partner was reported to be gay rather than straight, $F(1,205)=28.47, p<.001, R^{2}=.18$. Participants who held the belief that sexual orientation is a choice rated the ex-partner as unlikeable regardless of the expartner's sexual orientation, $F(1,205)=1.47, p=.23$. When the ex-partner was reported to be gay, participants who believe sexual orientation is a choice rated the ex-partner as significantly more unlikeable than participants who believe sexual orientation is innate, $F(1,205)=24.18, p<.001, R^{2}=.18$. There was no difference on likeability between participants with differing beliefs when the ex-partner was reported to be straight, $F(1,205)=.39, p$ $=.53$.

Honesty - Participants who held the belief that sexual orientation is innate rated the ex-partner as more honest when their ex-partner was reported to be gay rather than straight, $F(1,205)=26.12, p<.001, R^{2}=.27$. Participants who held the belief that sexual orientation is a choice rated the ex-partner as dishonest regardless of the expartner's reported sexual orientation, $F(1,205)=.62, p=.43$. When the ex-partner was said to be gay, participants who believe sexual orientation is innate rated the ex-partner as more honest than participants who believe sexual orientation is a choice, $F(1,205)=61.74, p<.001, R^{2}=.27$. There was no difference on perceived honesty between participants with differing beliefs when the ex-partner was reported to be straight, $F(1,205)=3.11, p=$ .08 .

Intention to harm - Participants who held the belief that sexual orientation is innate rated the ex-partner as intentionally attempting to harm them to a lesser extent when the ex-partner was reported to be gay rather than straight, $F(1,205)=38.23, p<.001, R^{2}=.23$, and participants who held the belief that sexual orientation is a choice showed a similar pattern, $F(1,205)=4.97, p=.03$. When the ex-partner was reported to be gay, participants who believe sexual orientation is a choice rated the ex-partner as intentionally trying to harm them to a greater extent than participants who believe sexual orientation is innate, $F(1,205)=23.68, p<.001, R^{2}=.23$. There was 
no difference on intention to harm between participants with differing beliefs when the ex-partner was reported to be straight, $F(1,205)=.53, p=.47$.

Harm to public identity - Participants who held the belief that sexual orientation is innate felt their public image was harmed to a lesser extent when the ex-partner was reported to be gay rather than straight, $F(1,205)=19.02$, $p<.001, R^{2}=.19$. Participants who held the belief that sexual orientation is a choice reported that their public image was harmed to a greater extent when the ex-partner was reported to be gay rather than straight, $F(1,205)$ $=3.75, p=.05$. When the ex-partner was said to be gay, participants who believe sexual orientation is a choice perceived greater harm to their public identity than participants who believe sexual orientation is innate, $F(1,205)$ $=44.45, p<.001, R^{2}=.19$. There were no differences between participants with differing beliefs for perceived damage to their public identity when the ex-partner was reported to be straight, $F(1,205)=.04, p=.83$.

\section{Mediated Moderation Model}

Following past research concerning threats to personal public identity, we hypothesized that participants' perception that the ex-partner was intentionally attempting to harm them and the perception that one's public identity was being damaged would mediate the relationship between the interaction (belief regarding the origin of sexuality by reported sexual orientation of ex-partner) and expressed anger (outcome). To test the hypothesized mediated moderation model we first conducted a series of regressions to show that the interaction significantly predicts the outcome variable (anger) and the mediators (intent to harm, harm to identity). We then conducted a regression showing that the mediators remain significant predictors of the outcome variable while the influence of the interaction on the outcome variable is significantly reduced when the mediators are included in the model.

In the first regression, we entered the independent variables belief of the origin of sexuality $(0=$ choice, $1=$ innate $)$ and ex-partner sexual orientation ( 0 = gay, $1=$ straight), and the interaction simultaneously to predict felt anger (see Table 2 for unstandardized betas, $t$-value, and level of significance). The interaction significantly predicted felt anger, $F(3,202)=15.39, p<.001, R^{2}=.19$ (Model 1). Subsequent regressions showed the interaction significantly predicted perceived intent to harm, $F(3,202)=19.62, p<.001, R^{2}=.23$ (Model 2), and perception of harm to one's public identity, $F(3,202)=15.71, p<.001, R^{2}=.19$ (Model 3). Lastly, a regression test showed that perceived intention of the ex-partner to harm one's public identity and perceived harm to one's public identity remained significant predictors, while the interaction was no longer a significant predictor of felt anger, $F(5,200)$ $=21.04, p<.001, R^{2}=.35$ (Model 4$)$.

Table 2

Mediated Moderation Analyses

\begin{tabular}{|c|c|c|c|c|c|c|c|c|}
\hline \multirow[b]{2}{*}{ Predictors } & \multicolumn{2}{|c|}{$\begin{array}{c}\text { Model } 1 \\
\text { Criterion: Anger }\end{array}$} & \multicolumn{2}{|c|}{$\begin{array}{c}\text { Model } 2 \\
\text { Criterion: Intention }\end{array}$} & \multicolumn{2}{|c|}{$\begin{array}{c}\text { Model } 3 \\
\text { Criterion: Harm Image }\end{array}$} & \multicolumn{2}{|c|}{$\begin{array}{c}\text { Model } 4 \\
\text { Criterion: Anger }\end{array}$} \\
\hline & $\boldsymbol{b}$ & $t$ & $b$ & $t$ & $\boldsymbol{b}$ & $t$ & $\boldsymbol{b}$ & $t$ \\
\hline Ex-Partner Sexual Orientation & -1.42 & $-2.30^{*}$ & -.57 & -0.82 & -2.61 & $-3.71^{\star *}$ & -.56 & -0.98 \\
\hline Belief of Origin of Sexual Orientation & -2.99 & $-4.87^{* *}$ & -2.75 & $-3.98^{* *}$ & -4.07 & $-5.82^{* *}$ & -1.37 & $-2.29^{*}$ \\
\hline Ex-Partner Sexual Orientation X Belief & 1.46 & $3.72^{\star *}$ & 1.26 & $2.85^{\star *}$ & 2.00 & $4.47^{* *}$ & .68 & 1.82 \\
\hline Intention to Harm Identity & & & & & & & .15 & $2.38^{*}$ \\
\hline Harm to Identity & & & & & & & .30 & $4.72^{\star \star}$ \\
\hline
\end{tabular}

${ }^{*} p<.05 .{ }^{* *} p<.01$. 
Using Preacher and Hayes' (2008) SPSS macro (5,000 iterations), we tested our prediction that perceived intent to harm and harm to public identity would mediate the relationship between the interaction and anger while controlling for the unique effects of the independent variables (belief about origin of sexual orientation and sexual orientation of ex-partner). As indicated by the absence of zero within the confidence interval $(95 \% \mathrm{Cl}=.4115$ to $1.285)$, the mediated moderation model was supported. Furthermore, intention to harm $(95 \% \mathrm{Cl}=.0506$ to .4159$)$ and perceived harm to public identity $(95 \% \mathrm{Cl}=.2901$ to 1.035$)$ were significant mediators of the relationship between interaction and anger.

\section{Discussion}

The purpose of the present study was to examine the influence of the belief of the origin of sexuality and sexual orientation of the ex-partner following the termination of a relationship on participants' emotional experience and perceived threat to one's public identity. Taking the perspective of the partner who did not initiate the breakup, we predicted and found, that participants who view sexual orientation as immutable perceived less harm to their public identity, reacted with less anger, and perceived the ex-partner more favorably when the ex-partner was gay (vs. straight), whereas participants who view sexual orientation as a choice expressed an equal degree of anger and negative evaluation of the ex-partner regardless of the ex-partner's sexual orientation. Indeed, participants who believe that sexual orientation is a choice perceived more harm to their identity when the ex-partner was purportedly gay (vs. straight). Furthermore, we predicted and found a mediated moderation model that showed the perception of the ex-partner's intention to harm one's public identity and perceived harm to that identity mediated the relationship between the interaction (sexual orientation of partner by belief of immutability of sexual orientation) and the experience of anger.

\section{Relationship Dissolution and Sexual Orientation}

Relationships exist within a wider network of social connections that have implications for the relationship identity (Felmlee \& Sprecher, 2000; Felmlee et al., 1990; Lewis, 1973), which is observed by others outside the relationship, and can influence individuals within the couple (Felmlee, 2001; Sprecher, 2011). The relationship has wide implications for the formation and maintenance of each relationship partners' self-concept (Aron et al., 2004; Chen et al., 2006). Partners within a relationship actively manage how the relationship is viewed by others (Afifi \& Steuber, 2009; Kunkel et al., 2003; Steuber \& Solomon, 2011), but also manage the impressions others have of themselves as an individual outside the relationship (Goffman, 1959; Leary, 1995; Schlenker, 1980). However, greater importance appears to be placed on maintaining the impression of oneself in the minds of others over that of maintaining others' impression of the relationship (Afifi et al., 2001; Afifi \& Steuber, 2009).

The present study supports past theorizing and research by showing differential reactions to relationship dissolution depending on the sexual orientation of the ex-partner and beliefs regarding the immutability of sexual orientation. In general, prior research shows that the perception that sexual orientation is uncontrollable, innate, or immutable is strongly associated with positive attitudes toward gays and lesbians and greater support for gay rights policies (Blackwell, 2008; Haider-Markel \& Joslyn, 2008; Haslam \& Levy, 2006; Herek \& Capitanio, 1995; Lewis, 2009; Whitley, 1990). Indeed, when the ex-partner was reported to be gay, those with the belief that sexual orientation is innate rated the ex-partner more favorably and expressed less anger than participants with the belief that sexual orientation is a choice. Interestingly, participants with a belief in the immutability of sexual orientation rated their ex-partner more unlikable and dishonest if the ex-partner was straight compared to gay. We suggest that this difference, plus the reduced ratings of threat to public identity, represents a reason for the breakup that can 
be communicated to others as a way to protect their individual public identity. However, for those with a view of sexual orientation as a choice this reason is absent because the ex-partner still chose to break off the relationship, thus leading to viewing the ex-partner as unlikable and dishonest regardless of their sexual orientation. Furthermore, the higher ratings of harm to their public identity when the ex-partner was reported to be gay (vs. straight) suggest that participants with a belief that sexual orientation is a choice may perceive greater difficulty in managing their individual public identities post breakup.

The present study was unique in manipulating the sexual orientation of an ex-partner and examining participants with widely different beliefs regarding the origin of sexual orientation. The results hold implications for research and understanding of the effects of essentialist beliefs on sexual orientation. Past research has shown that male participants (compared to female participants) generally endorse more negative attitudes toward gay men compared to lesbian women (Herek, 1988; Kite \& Whitley, 1996). The results of the present study showed that the gender of the participant did not affect ratings of the ex-partner. In other words, regardless of the gender of the participant, those with an innate belief rated the gay ex-partner more favorably than the straight ex-partner, while participants with a choice belief rated both gay and straight ex-partners unfavorably. Past research has also found heterosexual individuals' amount of contact with a gay or lesbian individual was related to lower negative attitudes (Anderssen, 2002; Bowen \& Bourgeois, 2001). While we only had participants imagine they were in a relationship (reported to be 2 years), those with the innate belief were more forgiving of the gay ex-partner while those with a choice belief were not.

The results of the present study also inform past findings in qualitative interview research with gay individuals after their breakup from a heterosexual relationship. In interviews with lesbians who had previously been in an opposite-sex marriage, respondents reported mixed reactions from ex-husbands reflecting either acceptance and support, or outright rejection (Thompson, Forsyth, \& Langley, 2009). The results of the present study offer an explanation for these findings. Perhaps the key difference between the ex-husbands in their differing reactions was their belief regarding the origin of sexual orientation. Those with immutable views of sexual orientation may have felt less public identity threat, less anger, and subsequently greater support, while those with choice beliefs felt more threat and anger leading to rejection of the ex-wife and possible retaliatory reactions.

\section{Relationship Dissolution as an Interpersonal Threat to Public Identity}

Interpersonal threats to public identity occur when another person is perceived to be illegitimately and intentionally attempting to undermine one's freedom to display a valued and distinctive public identity. Supporting past research, participants felt that the breakup harmed their public identity, perceived the ex-partner as intentionally attempting to harm their public identity, rated the ex-partner negatively (i.e., unlikeable, dishonest), and expressed anger when the ex-partner left the relationship. The results mirror those found in research examining other interpersonal threats to public identity in other social contexts (Gibson \& Reysen, 2012; Reysen et al., 2012; Snider \& Reysen, 2011). Indeed, we found that the breakup threatened participants, and the perception that another person is to blame for intentionally trying to harm one's public identity mediated the relationship between the breakup by belief interaction and the experience of anger. This result aids in explaining why individuals report feeling anger after being the non-initiator of a breakup (Perilloux \& Buss, 2008; Sbarra \& Emery, 2005; Sbarra \& Ferrer, 2006). In effect, compared to when the ex-partner was straight, participants with a belief that sexual orientation is innate believed the gay ex-partner was not intentionally attempting to harm their public identity and perceived less damage to their public identity, which resulted in less anger. 
Although we used sexual orientation of the ex-partner and participants' belief regarding sexual orientation to illustrate the interaction between the person and the situation after the termination of the relationship, we argue that relationship dissolution in general represents an interpersonal threat to public identity for the breakup recipient. The belief in the immutability of sexual orientation was shown to mitigate the negative reaction to the breakup when the ex-partner was gay (vs. straight). We suspect that in this situation individuals are afforded the opportunity to point to a cause for the breakup that is outside their control (i.e., it isn't my fault we broke up because my expartner is gay). Such an excuse may shield the breakup recipient's public identity. As such, there are other situations in which the breakup recipient can view the breakup initiator's behavior as uncontrollable or not intentional to manage others' impressions of the breakup recipient (e.g., ex-partner is joining a monastery or the ex-partner is taking a dream job in another location). Thus, the results of the present study are novel first and foremost in showing the influence of belief in the immutability of sexual orientation and sexual orientation of an ex-partner on emotions, person perception, and harm to identity. However, the results also provide an important illustration of relationship dissolution as an interpersonal threat to public identity.

\section{Limitations}

The present study was limited in the use of vignettes to induce the threat to participants' public identity. Participants may have relied on lay theories of how they would react to the dissolution of the relationship that may differ if they were experiencing the same event in everyday life. Prior research argues against this interpretation (Reysen et al., 2012; Robinson \& Clore, 2001). Vignettes can often elicit similar reactions to those exhibited in real life and realistic laboratory studies. Furthermore, manipulating the actual experience described in the vignettes would be potentially unethical, and difficult to study in naturally occurring romantic dyads. The purpose of the study was to examine the mechanisms that lead to anger after a breakup rather than examining the intensity of anger. Although the intensity of the emotional response in real life situations may differ, we suggest that the mechanisms leading to felt anger will remain the same. A second limitation is that participants in the gay ex-partner conditions may have perceived the ex-partner as bisexual rather than gay. Future research may explicitly manipulate this distinction to examine if results vary depending on the perceived fluidity of the ex-partner's sexuality. A third limitation is that participants may have (knowingly or unknowingly) inaccurately rated their sexual orientation on the confidential prescreening measure. Thus, non-heterosexuals may have participated in the present research. Participants providing inaccurate responses are a concern for the majority of social scientific research, this study included. Lastly, one could argue that heterosexual participants who believe that sexuality is immutable would be unable to conceive of a partner leaving for a same-sex relationship. Because an estimated $90 \%$ of gay men and lesbians have reported engaging in opposite-sex relations (Diamond, Savin-Williams, \& Dubé, 1999), we suggest that learning an ex-partner is gay is plausible. Thus, although one may believe that sexuality is immutable does not mean that forces outside of sexual drives (e.g., stigma to adhere to heterosexual norm, exploration or confirmation of sexual orientation) may serve as possible reasons for the ex-partner to have engaged in a cross-sexual relationship.

\section{Conclusion}

The results of the present study support the notion that relationship dissolution is experienced as an interpersonal threat to one's public identity for the non-initiator of the breakup. Individuals with a belief in the immutability of sexual orientation reacted to a breakup with less anger, more positive perception of the ex-partner (likeable, honest), less harm to their public identity, and less perceived intent of the initiator of the breakup to harm their identity when the ex-partner was gay compared to straight. Individuals with a belief that sexual orientation is a 
choice felt angry and rated the ex-partner negatively regardless of the ex-partner's sexual orientation. Furthermore, those with a choice belief felt their public identity was more damaged when the ex-partner was gay compared to straight. A mediated moderation analysis showed that, compared to when the ex-partner was straight, participants with a belief that sexual orientation is innate believed the gay ex-partner was not intentionally attempting to harm their public identity and perceived less damage to their public identity, which resulted in less anger. While research in psychology on personal relationships often focuses on individual differences or intraindividual emotions and types (e.g., attachment styles), we concur with others (Felmlee, 2001; Holmes, 2000; Sprecher, 2011) that greater attention is needed on the interaction between the relationship couple and the context or situation in which those relationships are embedded.

\section{Notes}

1) Because only participants scoring high on a measure of sexual orientation were allowed to participate in the present study, men $(M=6.91, S D=0.29)$ and women $(M=6.84, S D=0.36)$ rated their sexuality near the heterosexual end-point of the 7-point Likert-type scale. Because only participants scoring either low (reflecting a belief that sexuality is a choice) or high (reflecting a belief that sexuality is innate) on a 7-point Likert-type measure of belief in the immutability of sexuality were eligible to participate in the present study, participants in the choice conditions (Men: $M=2.36, S D=0.53$; Women: $M=2.29, S D=$ 0.53 ) showed low ratings while participants in the innate conditions (Men: $M=5.74, S D=0.50$; Women: $M=5.66, S D=0.53$ ) showed high ratings.

2) We also conducted a MANOVA including gender of participant and current relationship status (single vs. in a relationship) as independent variables. The main effects and interactions were non-significant. Therefore, the results are presented collapsed across participant gender and current relationship status.

3) The omnibus tests for the main effect of belief of origin (Wilks' $\Lambda=.79, F(5,197)=10.24, p<.001, \eta_{p}^{2}=.21$ ) and the ex-partner's sexual orientation (Wilks' $\Lambda=.76, F(5,197)=12.60, p<.001, \eta_{p}^{2}=.24$ ) were also significant, but were qualified by the interaction. Therefore, only the interaction is discussed.

\section{References}

Afifi, T., \& Steuber, K. (2009). The Revelation Risk Model (RRM): Factors that predict the revelation of secrets and the strategies used to reveal them. Communication Monographs, 76, 144-176. doi:10.1080/03637750902828412

Afifi, W. A., Falato, W. L., \& Weiner, J. L. (2001). Identity concerns following a severe relational transgression: The role of discovery method for the relational outcomes of infidelity. Journal of Social and Personal Relationships, 18, 291-308. doi:10.1177/0265407501182007

Anderssen, N. (2002). Does contact with lesbians and gays lead to friendlier attitudes? A two year longitudinal study. Journal of Community \& Applied Social Psychology, 12, 124-136. doi:10.1002/casp.665

Aron, A., McLaughlin-Volpe, T., Mashek, D., Lewandowski, G., Wright, S. C., \& Aron, E. N. (2004). Including others in the self. European Review of Social Psychology, 15, 101-132. doi:10.1080/10463280440000008

Blackwell, C. W. (2008). Belief in the "free choice" model of homosexuality: A correlate of homophobia in registered nurses. Journal of LGBT Health Research, 3, 31-40. doi:10.1080/15574090802093117

Bowen, A. M., \& Bourgeois, M. J. (2001). Attitudes toward lesbian, gay, and bisexual college students: The impact of contribution of pluralistic ignorance, dynamic social impact, and contact theories. Journal of American College Health, 50, 91-96. doi:10.1080/07448480109596012

Chen, S., Boucher, H. C., \& Tapias, M. P. (2006). The relational self revealed: Integrative conceptualization and implications for interpersonal life. Psychological Bulletin, 132, 151-179. doi:10.1037/0033-2909.132.2.151 
Davis, D., Shaver, P. R., \& Vernon, M. L. (2003). Physical, emotional, and behavioral reactions to breaking up: The roles of gender, age, emotional involvement, and attachment style. Personality and Social Psychology Bulletin, 29, 871-884. doi:10.1177/0146167203029007006

Diamond, L. M., Savin-Williams, R. C., \& Dubé, E. M. (1999). Sex, dating, passionate friendships, and romance: Intimate peer relations among lesbian, gay, and bisexual adolescents. In W. Furman, C. Feiring, \& B. B. Brown (Eds.), Contemporary perspectives on adolescent romantic relationships (pp. 175-210). New York: Cambridge University Press.

Doering, J. (2010). Face, accounts, and schemes in the context of relationship breakups. Symbolic Interaction, 33, 71-95. doi:10.1525/si.2010.33.1.71

Falomir-Pichastor, J. M., \& Mugny, G. (2009). “'m not gay... I'm a real man!": Heterosexual men's gender self-esteem and sexual prejudice. Personality and Social Psychology Bulletin, 35, 1233-1243. doi:10.1177/0146167209338072

Felmlee, D. H. (2001). No couple is an island: A social network perspective on dyadic stability. Social Forces, 79, 1259-1287. doi:10.1353/sof.2001.0039

Felmlee, D. H., \& Sprecher, S. (2000). Close relationships and social psychology: Intersections and future paths. Social Psychology Quarterly, 63, 365-376. doi:10.2307/2695846

Felmlee, D. H., Sprecher, S., \& Bassin, E. (1990). The dissolution of intimate relationships: A hazard model. Social Psychology Quarterly, 53, 13-30. doi:10.2307/2786866

Gibson, S., \& Reysen, S. (2012). Plagiarism as a threat to public identity. International Journal of Business and Public Administration, 9, 78-86.

Goffman, E. (1959). The presentation of self in everyday life. Garden City, NY: Doubleday.

Gottman, J. M., Levenson, R. W., Gross, J., Fresderickson, B. L., McCoy, K., Rosenthal, L., . . Yoshimoto, D. (2003). Correlates of gay and lesbian couples' relationship satisfaction and relationship dissolution. Journal of Homosexuality, 45, $23-43$. doi:10.1300/J082v45n01_02

Greenberg, J., \& Pyszczynski, T. (1985). Compensatory self-inflation: A response to the threat to self-regard of public failure. Journal of Personality and Social Psychology, 49, 273-280. doi:10.1037/0022-3514.49.1.273

Haider-Markel, D. P., \& Joslyn, M. R. (2008). Beliefs about the origins of homosexuality and support for gay rights: An empirical test of attribution theory. Public Opinion Quarterly, 72, 291-310. doi:10.1093/poq/nfn015

Haslam, N., \& Levy, S. R. (2006). Essentialist beliefs about homosexuality: Structure and implications for prejudice. Personality and Social Psychology Bulletin, 32, 471-485. doi:10.1177/0146167205276516

Hegarty, P. (2002). 'It's not a choice, it's the way we're built': Symbolic beliefs about sexual orientation in the US and Britain. Journal of Community \& Applied Social Psychology, 12, 153-166. doi:10.1002/casp.669

Hegarty, P., \& Pratto, F. (2001). Sexual orientation beliefs: Their relationship to anti-gay attitudes and biological determinist arguments. Journal of Homosexuality, 41, 121-135. doi:10.1300/J082v41n01_04

Heider, F. (1958). The psychology of interpersonal relations. New York: Wiley. 
Herek, G. M. (1988). Heterosexuals' attitudes toward lesbians and gay men: Correlates and gender differences. Journal of Sex Research, 25, 451-477. doi:10.1080/00224498809551476

Herek, G. M., \& Capitanio, J. P. (1995). Black heterosexuals' attitudes toward lesbians and gay men in the United States. Journal of Sex Research, 32, 95-105. doi:10.1080/00224499509551780

Holmes, J. G. (2000). Social relationships: The nature and function of relational schemas. European Journal of Social Psychology, 30, 447-495. doi:10.1002/1099-0992(200007/08)30:4<447::AID-EJSP10>3.0.CO;2-Q

Hortacsu, N., \& Karanci, A. N. (1987). Premarital breakups in a Turkish sample: Perceived reasons, attributional dimensions and affective reactions. International Journal of Psychology, 22, 57-74. doi:10.1080/00207598708246767

Kite, M. E., \& Whitley, B. E., Jr. (1996). Sex differences in attitudes toward homosexual persons, behavior and civil rights: A meta-analysis. Personality and Social Psychology Bulletin, 22, 336-353. doi:10.1177/0146167296224002

Kunkel, A. D., Wilson, S. R., Olufowote, J., \& Robson, S. (2003). Identity implications of influence goals: Initiating, intensifying, and ending romantic relationships. Western Journal of Communication, 67, 382-412. doi:10.1080/10570310309374780

Leary, M. R. (1995). Self-presentation: Impression management and interpersonal behavior. Madison, WI: Brown \& Benchmark.

Leary, M. R., Landel, J. L., \& Patton, K. M. (1996). The motivated expression of embarrassment following a self-presentational predicament. Journal of Personality, 64, 619-636. doi:10.1111/j.1467-6494.1996.tb00524.x

Lewandowski, G. W., Jr, Aron, A., Bassis, S., \& Kunak, J. (2006). Losing a self-expanding relationship: Implications for the self-concept. Personal Relationships, 13, 317-331. doi:10.1111/j.1475-6811.2006.00120.x

Lewis, G. B. (2009). Does believing homosexuality is innate increase support for gay rights? Policy Studies Journal, 37, 669-693. doi:10.1111/j.1541-0072.2009.00330.x

Lewis, R. A. (1973). Social reaction and the formation of dyads: An interactionist approach to mate selection. Sociometry, 36, 409-418. doi:10.2307/2786342

Lyons, A., Reysen, S., \& Pierce, L. (2012). Video lecture format, student technological efficacy, and social presence in online courses. Computers in Human Behavior, 28, 181-186. doi:10.1016/j.chb.2011.08.025

Morgan-Lopez, A. A., \& MacKinnon, D. P. (2006). Demonstration and evaluation of a method for assessing mediated moderation. Behavior Research Methods, 38, 77-87. doi:10.3758/BF03192752

Muller, D., Judd, C. M., \& Yzerbyt, V. Y. (2005). When moderation is mediated and mediation is moderated. Journal of Personality and Social Psychology, 89, 852-863. doi:10.1037/0022-3514.89.6.852

Perilloux, C., \& Buss, D. M. (2008). Breaking up romantic relationships: Costs experienced and coping strategies deployed. Evolutionary Psychology, 6, 164-181.

Preacher, K. J., \& Hayes, A. F. (2008). Asymptotic and resampling strategies for assessing and comparing indirect effects in multiple mediator models. Behavior Research Methods, 40, 879-891. doi:10.3758/BRM.40.3.879

Reysen, S. (2005). Construction of a new scale: The Reysen likeability scale. Social Behavior and Personality, 33, 201-208. doi:10.2224/sbp.2005.33.2.201 
Reysen, S. (2008, April). Construction and validation of measures of perceived honesty and expertise. Poster presented at the 54th annual Southwestern Psychological Association conference, Kansas City, MO.

Reysen, S., Landau, M. J., \& Branscombe, N. R. (2012). Copycatting as a threat to public identity. Basic and Applied Social Psychology, 34, 226-235. doi:10.1080/01973533.2012.674418

Robinson, M. D., \& Clore, G. L. (2001). Simulation, scenarios, and emotional appraisal: Testing the convergence of real and imagined reactions to emotional stimuli. Personality and Social Psychology Bulletin, 27, 1520-1532.

doi:10.1177/01461672012711012

Sbarra, D. A., \& Emery, R. E. (2005). The emotional sequelae of nonmarital relationship dissolution: Analysis of change and intraindividual variability over time. Personal Relationships, 12, 213-232. doi:10.1111/j.1350-4126.2005.00112.x

Sbarra, D. A., \& Ferrer, E. (2006). The structure and process of emotional experience following nonmarital relationship dissolution: Dynamic factor analyses of love, anger, and sadness. Emotion, 6, 224-238. doi:10.1037/1528-3542.6.2.224

Schlenker, B. R. (1980). Impression management: The self-concept, social identity, and interpersonal relations. Monterey, CA: Brooks/Cole.

Simpson, J. A. (1987). The dissolution of romantic relationships: Factors involved in relationship stability and emotional distress. Journal of Personality and Social Psychology, 53, 683-692. doi:10.1037/0022-3514.53.4.683

Snider, J. S., \& Reysen, S. (2011). Gossip: Beliefs and reactions. Manuscript in preparation.

Sprecher, S. (2011). The influence of social networks on romantic relationships: Through the lens of the social network. Personal Relationships, 18, 630-644. doi:10.1111/j.1475-6811.2010.01330.x

Steuber, K. R., \& Solomon, D. H. (2011). Factors that predict married partners' disclosures about infertility to social network members. Journal of Applied Communication Research, 39, 250-270. doi:10.1080/00909882.2011.585401

Thompson, C. Y., Forsyth, C. J., \& Langley, K. (2009). Transiting social worlds: Accounts of formerly married lesbians. Sociological Focus, 42, 373-393. doi:10.1080/00380237.2009.10571363

Whitley, B. E., Jr. (1990). The relationship of heterosexuals' attributions for the causes of homosexuality to attitudes toward lesbians and gay men. Personality and Social Psychology Bulletin, 16, 369-377. doi:10.1177/0146167290162016 